http://dx.doi.org/10.30681/23588403v12i035259

\title{
DESVIOS NA LINGUAGEM EM PRODUÇÕES DE ESCOLAS PÚBLICAS
}

\author{
Narumi ITO (UNEMAT) ${ }^{1}$ \\ Vanessa Fabiola S. FARIA (UNEMAT) ${ }^{2}$
}

Data de recebimento: 31/01/2019

Aceite: 05/05/2019

Resumo: Este presente artigo propõe analisar diversas produções textuais de estudantes do último ano do ensino médio de escolas públicas brasileiras. Para tanto, o trabalho será direcionado pelos estudos linguísticos, especificamente a Fonética e a Fonologia. Neste sentido, o nosso embasamento teórico envolverá as pesquisadoras brasileiras Zuleica de Sousa Barros, Stella Maris Bortoni-Ricardo, Janainna Alves de F. R. Dias, Élida Paulina Ferreira e Darcilia Simões.

Palavras-Chave: Desvios na linguagem; Fonética e Fonologia; Escolas públicas

Abstract: This article proposes to analyze several textual productions of high school seniors from Brazilian public schools. To do so, the work will be directed by linguistic studies, specifically Phonetics and Phonology. In this sense, our theoretical background will involve researchers Brazilians Zuleica de Sousa Barros, Stella Maris Bortoni-Ricardo, Janainna Alves de F. R. Dias, Élida Paulina Ferreira and Darcilia Simões.

Keywords: Deviations in language; Phonetics and Phonology; Public schools

\section{DESVIOS NA LÍNGUA ESCRITA}

Tendo em vista o contexto histórico de que o Brasil foi colonizado principalmente pelos portugueses, inicialmente em 1500, devemos considerar que o país não era inabitado, pois residiam milhares de povos indígenas, logo, já haviam línguas, culturas e normas de acordo com as suas condições e os seus costumes. Porém, juntamente com as grandes navegações da Europa, eles trouxeram a sua Língua Portuguesa e consequentemente, as suas formas de viver. Portanto, percebemos até nos dias atuais, como a língua escrita é repleta de acentos, como se fosse uma forma de aprendermos a falar, através da escrita. Mas, muito pelo contrário, os

\footnotetext{
${ }^{1}$ Graduanda do $7^{\circ}$ semestre do curso de Licenciatura Plena em Letras - Inglês, pela Universidade do Estado de Mato Grosso - UNEMAT, no campus de Pontes e Lacerda - MT. narumiito@ hotmail.com

2 Possui graduação em Letras - habilitação em Alemão e Português pela Universidade de São Paulo (2004), mestrado em Educação pela Faculdade de Educação da USP e doutorado em Linguística pelo Programa de Pós Graduação em Estudos da Linguagem - CCHLA- UFRN. Atualmente é professora da Universidade do Estado de Mato Grosso, no campus de Pontes e Lacerda - MT. Tem experiência na área de Letras, especificamente nos Estudos de Texto, Metodologia do Ensino da Língua Portuguesa e Estágio Supervisionado. vanessafabiola@unemat.br
} 


\section{Revista de Estudos Acadêmicos de Letras}

linguistas notaram que quem exerce o papel de influenciador é a fala, tornando a escrita, representação da oralidade.

Neste sentido, o artigo busca analisar 7 textos de alunos do $3^{\circ}$ ano do ensino médio, de uma escola pública brasileira, pautando-se nos estudos linguísticos, especificamente a Fonética e a Fonologia. Para tanto, nosso embasamento teórico envolverá os pesquisadores Zuleica de Sousa Barros, por meio do artigo Análise dos "erros" ortográficos na escrita infantil, Stella Maris Bortoni-Ricardo, com o livro Educação em língua materna: a sociolinguística aplicada na sala de aula (2004), Janainna Alves de F. R. Dias e Élida Paulina Ferreira, com o artigo Desvios na escrita: Projeções fonético-fonológicas ou consequências do sistema ortográfico? O ensino reflexivo da ortografia (2015) e Darcilia Simões, através do livro Considerações sobre a fala e a escrita: fonologia em nova chave (2006).

Assim, para a professora doutora da Universidade de Brasília (UnB), Bortoni-Ricardo, o país ainda não perdeu o "hábito" de acreditar/confiar que os modelos internacionais são melhores e que para dar certo, realmente precisamos copiar a metodologia de outros lugares:

No Brasil, ainda não se conferiu a devida atenção à influência da diversidade linguística no processo educacional. A ciência linguística vem, timidamente, apontando estratégias que visam aumentar a produtividade da educação e preservar os direitos do educando. Essa contribuição será tanto mais efetiva

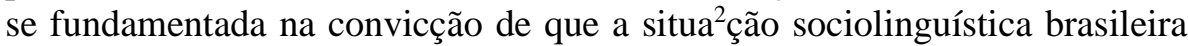
apresenta peculiaridades que a distinguem da de outros países. As atividades científicas na área, não se podem restringir, portanto, a uma simples importação. É indispensável o desenvolvimento de um aparato teóricometodológico adequado á realidade nacional (BORTONI-RICARDO, 2005, p. 19).

Dessa forma, a pesquisadora defende que não devemos importar metodologias de ensino e aprendizagem de outros países, uma vez que, deve ser levado em conta as dificuldades específicas de cada contexto geográfico. Além disso, o aluno tem o seu tempo para aprender, tendo em vista que ninguém possui conhecimento de mundo tal qual o outro, cada estudante tem as suas próprias experiências e por isso, necessita de um sistema que consiga se adequar as suas dificuldades, não ele ter que seguir um padrão pré-estabelecido. 
Para Barros, "a reflexão acerca do modo de pensar e vivenciar os eventos de escrita pode evidenciar que é impossível o ensino e a aprendizagem de uma língua sem o conhecimento de sua estrutura e funcionamento". Dessa forma, a autora defende que antes de qualquer coisa, a escrita deve ser sistematizada, estudando as suas particularidades e delimitando os seus aspectos. Neste contexto, grande parte dependerá dos educadores, o objetivo é criarem alternativas pedagógicas para não condenarem os erros dos seus alunos, mas buscarem através deles, compreenderem o sentido de tais desvios na linguagem e, portanto, procurarem as soluções pertinentes.

De acordo com Dias e Ferreira (2015), os “erros” ortográficos acontecem, pois, a língua possui características regulares e irregulares, ao contrário dos regulares que são "previsíveis", podem ser compreendidos por meio de reflexões:

Os aspectos ortográficos irregulares não podem ser explicados através de regras, foram assim canonizadas em virtude da etimologia da palavra ou porque ao longo da história determinada "tradição de uso" se tornou convencional, como é o caso do emprego dos grafemas $\langle\mathrm{g}\rangle$ e $\langle\mathrm{j}\rangle$. Para o aluno registrar em seu léxico a ortografia de palavras irregulares é importante que estas façam parte da rotina deles, a fim de a memorização ocorrer de forma mais fácil, menos sofrível (DIAS \& FERREIRA, 2015, p. 04).

Portanto, as palavras irregulares exigem que os alunos exercitem a ortografia convencional e internalizem, por exemplo, através da memória fotográfica. Levando em conta que diferente dos regulares, que possuem regras inteligíveis, os irregulares não têm uma gramática específica para descrevê-los, mas necessitam da prática e da fixação individual.

Conforme Simões (2006), Fonética pode ser definida como: "parte dos estudos linguísticos que se ocupa do levantamento de todos os sons produzidos pelos falantes - sons da fala - com vistas a viabilizar as distinções dialetais que caracterizam comunidades linguísticas”. Neste sentido, vale ressaltar os aspectos geográficos (variações diatópicas), sociais (variações diastráticas) ou mesmo individuais (variações diafásicas). Um exemplo citado pela autora sobre o que os estudos fonéticos objetivam, se refere ao uso da palavra gosto, especificamente as várias maneiras de representar os fonemas $[\mathrm{s}]$ e $[\mathrm{t}]$. No falar carioca, a pronúncia é chiante do travador de sílaba /s/ e seguida de oclusiva dental/t/. No falar sulista, a pronúncia sibilante do travador /s/ é seguida de oclusiva dental /t/, e no falar caipira, a pronúncia chiante do travador $/ \mathrm{tF} /$ e da oclusiva dental /t/ (palatalizada). Mas, apesar dos vários fonemas, de acordo com o espaço geográfico, a semântica persevera o mesmo em todos os casos. 


\section{Revista de Estudos Acadêmicos de Letras}

Portanto, a fonologia soluciona as variações através do arquifonema, no caso apresentado, por exemplo, as variáveis são resumidas no arquifonema sibilante /S/. Ainda que observada a variação alofônica /t/ e /tF/ - realizações foneticamente distintas de um mesmo fonema - pode-se concluir pela irrelevância do fato sob o prisma fonológico, dado que tal variação (ou alofonia) não produz alteração no signo: o significado do vocábulo se mantém, independente da pronúncia, seja ela "a", "b" ou "c". Vale ressaltar que a Fonologia ou fonêmica:

Parte da linguística que se ocupa dos sons da língua, ou seja, levanta, classifica e estabelece as distinções básicas entre os fonemas de uma língua, visando à descrição de sua estrutura fônica, o que possibilita distingui-la de outras línguas e definir seu padrão combinatório no nível da sílaba (...) Assim, a fonologia não leva em conta as diferenças dialetais, ocupando-se tão somente das diferenças fonemáticas (entre um fonema e outro, como /p/ e /b/, por exemplo), as quais produzem as distinções entre significantes e significados numa língua (SIMÕES, 2006, p. 06).

Neste contexto, percebemos claramente a distinção entre Fonética e Fonologia, já que a primeira detém seus estudos as diversas características próprias das comunidades de fala, as quais não transformam o significado, apenas os sons produzidos pelos falantes. Enquanto a Fonologia, ao contrário da Fonética, se interessa em descrever as estruturas fônicas, com o intuito de perceber a variação semântica, como por exemplo a ausência ou presença do fonema /s/, que determina o singular ou o plural da palavra.

\section{OBJETO ANÁLITICO: CADERNOS DE PRODUÇÃO TEXTUAL}

O presente artigo propõe discutir sobre alguns dos principais desvios ortográficos, para tanto, o recorte compõe-se de trechos de 7 textos, todos de alunos no último ano do ensino médio de uma escola pública brasileira. Dessa forma, tornou-se perceptível a recorrência da perda dos acentos agudos, graves, circunflexos e o til, como se realmente não necessitássemos da acentuação gráfica para nos lembrarmos do som dos significantes. Além disso, notou-se variações gráficas, principalmente entre os fonemas /s/ e /z/, /s/ e /x/, /u/ e /1/, /u/ e /o/, a ocorrência de alçamento, pois a vogal média-alta [e] é elevada à vogal alta [i] e vice-versa, entre outros desvios fonéticos e fônicos.

TEXTO 1: "A importancia da leitura para a o dominio da escrita"

“(...). É fundamental que as pessoas compreendam o que nos falamos e escrevemos, para isso, é necessário saber usar de forma correta e adequada a 


\section{Revista de Estudos Acadêmicos de Letras}

lingua portuguesa (...) não se trata apenas de ler, mas de entender o que está implicito nos fatos noticíados, a final até os meios de comunicasão não são totalmente isentos é e importante para que nós possamos construir uma opiniao própria sobre o fato(...)"

Neste primeiro texto, notamos 3 casos de falta de acento agudo, nas palavras domínio, língua e implícito. Outra recorrência é a inexistência do acento circunflexo e til em importância e opinião, além disso, o excesso do acento agudo também apareceu em noticíados, por último houve a variação gráfica entre os fonemas /s/ e /ç/, no significante comunicação.

\section{TEXTO 2: "Preconceito racial"}

“(...). Sabe que a maior parte de uma população são negros, pardos e indios e a menoria são brancos, e mesmo assim a maioria é o que sofrem preconceito. As pessoas jugam pela cor ou raça da pessoa, não se ela e capaz de realizar algo (...). O Brasil sendo um Pais democratico todos deveria ter o entendimento que temos os mesmos direitos não so por que as pessoas tem cor diferente significa que é menos."

Primeiramente, pode-se observar a ausência dos acentos agudos em índios, democrático, só e país, além dessa falta, o "país" foi grafado em letra maiúscula, mas mantendo o sentido. Outra peculiaridade é a troca do fonema /i/ pelo /e/, em menoria, o significado prevaleceu o mesmo, mas conforme a norma culta da Língua Portuguesa, a grafia se encontra errada. Há uma ocorrência da síncope, em julgam, pela supressão do fonema /1/. Por fim, há problemas de concordância verbal e nominal, tendo em vista: "todos deveriam", onde falta pluralizar o verbo e "as pessoas tem", notamos a falta do acento circunflexo no têm. Neste trecho: "e mesmo assim a maioria é o que sofrem preconceito", percebemos que não há concordância verbal, nem a nominal, gramaticalmente, o correto seria "e mesmo assim a maioria são os que sofrem preconceito".

TEXTO 3: "Texto dramático"

“(...)Aquilo deixou todos os corações dos familiares, mais não podia decepicionar ele pois ele pedeu que não fizesse a cirrugia. Mais aqueles últimos foi os melhores, estava treste mais junto com ele brincando e conversando (...) uma pessoa que tenha uma historia incriveu.

Neste trecho, reparamos a influência da fala sob a escrita, quando o estudante escreve "decepicionar", ao invés de decepcionar, novamente a falta de concordância ao falar "foi os 


\section{Revista de Estudos Acadêmicos de Letras}

melhores" ao invés de foram os melhores. A repetição do sujeito também chama a atenção, a troca dos fonemas /i/ pelo /e/, nas palavras pediu e triste. Em incrível, reparamos a troca do /// pelo /u/. Em cirurgia, há a ocorrência de paragoge, ou seja, a inserção de segmentos, adição de um segmento a uma palavra, como em ante $\sim$ antes. Fonologicamente analisando, o conectivo adversativo, "mas", foi usado de maneira inapropriada no texto, uma vez que o aluno usou "mais" - classificação de adição.

TEXTO 4: "Pessoas com sutaques diferentes"

"Conheci um menino chamado (...), ele veio de (...), e o sutaque dele é bem diferente, pelo jeito eles puxam bastante o "R" e trocam bastante o "O" pelo "U", e muitas coisas são faladas diferentes tipo "espia" que leva o sentido de olha ai, e outra palavra que achei bem diferente foi "pia" que significa menino ele disse que estranhou muito no começo, mais achou nossa forma (...)"

Compreende-se novamente a ocorrência da troca entre os fonemas /o/ e /u/ na palavra sotaque, no trecho escrita com u, além disso, constata-se características fonológicas, no "olha ai" que possivelmente seria "olha aî" e no "pia", que de acordo com o contexto, pode-se concluir que a forma gráfica deveria ser "piá", torna-se importante refletir sobre esses desvios fônicos, pois eles mudam o sentido da palavra, e portanto, a interpretação do que o locutor pretende enunciar para o alocutário.

TEXTO 5: "Texto dramático"

“(...) Eu adorava quando chegava aos feriados festivo dos domingos, que todos os primos vinha tambem, nós brincava de varias brincadeira. Mais sempre ela estava comigo a mimosa, um dia de banho na mimosa, e pedi para meu pai para deixar ela durmir comego. Quando ja estava dormindo o telefone do meu pai tocou, e veu a noticia que meu avô tenha passado mal e meu tio levou para cidade e para o hospital (...)"

No texto 5, reparamos a falta de concordância em relação aos feriados festivos, que no trecho não se encontra no plural, mas no singular. Bem como em brincadeiras, que novamente está no singular, porém, de acordo com a gramática, deveria estar no plural. Sem falar, nos seguintes verbos vinham e brincavam. Outra variação fonológica, está na troca do /o/ pelo /u/ em dormir, o /i/ pelo /e/ em comigo e tinha, o /io/ pelo / $\mathrm{u} / \mathrm{em}$ veio. Para finalizar, analisamos a falta dos acentos agudos em diversas palavras, como: também, já e várias. 


\section{TEXTO 6: "Quem Sou Eu"}

"Nasci na cidade (...). Estou solteiro e não tenho filhos. Sempre quiz ser jogador de futebol desde criança já jogava bola no canpinho de terra, na época eu jogava com bola feita de meia porque meus pais não tinha condição de comprar uma bola boa pra mim, é por isso que valorizo tudo que tenho hoje $(\ldots) "$

Neste trecho, inicialmente os significantes "Sou/Eu" no tema da produção textual, são escritos em letras maiúsculas desnecessariamente, apesar de não se transformarem semanticamente. Neste contexto, percebemos a variação gráfica entre os fonemas /s/ e /z/ em quis, o qual foi grafado com z, outra troca foi entre $\mathrm{o} / \mathrm{n} / \mathrm{e} \mathrm{o} / \mathrm{m} /$, pois ao invés do $\mathrm{m}$, o aluno utilizou o n para escrever campinho, por isso, tem-se a ocorrência de um caso bilabial na troca do m para o n, bilabial pela língua-alveolar. Finalmente, também notamos a discordância verbal na frase "meus pais não tinha", ortograficamente, o certo seria "meus pais não tinham".

TEXTO 7: "A moça rica e o rapaz pobre"

“(...) Nesta faculdade Alicia conheceu um rapaz, lindo, charmoso e rico do jeito que sua familia queria, o nome dele era Guilerme. Alicia passou a convever com Guilerme (...) os dois ficaram olhando um para o outro e relembrou o passado e começou a chorar.

No texto 7, nota-se que existem menos recorrências dos desvios da linguagem, mesmo assim em família, há a supressão do acento agudo. Em conviver, o /i/ é trocado pelo fonema /e/, possivelmente por várias palavras que se escreve com /e/, mas que se pronúncia com /i/ em muitas regiões, como, por exemplo: leite e dente. Por fim, também deveria acontecer a concordância verbal em relembraram e começaram, pois no texto, se encontram no singular, ao invés do plural.

\section{Considerações finais}

Por meio destes textos, percebemos que as recorrências dos desvios na linguagem geralmente são de ordem fonética, ou seja, se sobrepõe em relação as de ordens fonológicas. Além disso, outro aspecto que chamou muito a atenção foi a dificuldade em usar os acentos gráficos, como se os alunos não precisassem de regras para ajudarem eles na oralidade, uma 


\section{Revista de Estudos Acadêmicos de Letras}

vez que antes de aprenderem a escrever, já possuem contato com a língua mãe - portuguesa e, portanto, não precisam de normas que moldem o jeito deles falarem.

\section{REFERÊNCIAS}

BARROS, Zuleica de Sousa. Análise dos “erros" ortográficos na escrita infantil: Considerações sobre a oralidade e a escrita, UFC.

BORTONI-RICARDO, Stella Maris. Educação em língua materna: a sociolinguística aplicada na sala de aula. São Paulo: Parábola, 2004.

DIAS, Janainna Alves de Freitas Rocha. FERREIRA, Élida Paulina. Desvios na escrita: Projeções fonético-fonológicas ou consequências do sistema ortográfico? O ensino reflexivo da ortografia. Caderno de Letras, $n^{\circ} 24$, Jan-Jun- 2015

SIMÕES, Darcilia. Considerações sobre a fala e a escrita: fonologia em nova chave. São Paulo: Parábola Editorial, 2006. 